\title{
ALTERASI DAN MINERALISASI DI PULAU MERAH, KECAMATAN PESANGGARAN, KABUPATEN BANYUWANGI, PROVINSI JAWA TIMUR
}

\section{ALTERATION AND MINERALIZATION IN RED ISLAND, PESANGGARAN DISTRICT, BANYUWANGI REGENCY, EAST JAVA PROVINCE}

\author{
Sabtanto Joko Suprapto', Dodid Murdohardono', Suparno', \\ Oman Abdurahman ${ }^{2}$, dan Agung Tri Subekti ${ }^{3}$ \\ ${ }^{1}$ Politeknik Energi dan Mineral Akamigas \\ ${ }^{2}$ Museum Geologi \\ ${ }^{3}$ Dinas ESDM, Provinsi Jawa Timur \\ sabtanto_js@yahoo.com
}

\section{SARI}

Pulau Merah berada di Desa Sumberagung, Kecamatan Pesanggaran, Kabupaten Banyuwangi, pada jarak sekitar 200 meter dari garis pantai Desa Sumberagung, memiliki indikasi mineralisasi logam. Penelitian di Pulau Merah bertujuan untuk mendapatkan tipe mineralisasi dan alterasi, serta sebaran tubuh bijih. Metodologi penelitian yang digunakan terdiri dari pengamatan litologi, alterasi, mineralisasi, dan pengambilan conto batuan untuk analisis kandungan mineral dan kimia. Morfologi Pulau Merah berbentuk bukit kecil. Pada tebing bagian timur menghadap laut dangkal yang dapat diseberangi saat laut surut, terdapat singkapan luas batuan teralterasi dan mineralisasi. Pada bagian tenggara sampai bagian tengah terdapat singkapan cebakan tembaga porfiri, di bagian utara terdapat singkapan cebakan emas epitermal tipe high sulphidation. Cebakan tembaga porfiri mempunyai kadar $0,32 \%$ s.d. $2,14 \%$ Cu, 285 ppb s.d. 1.502 ppb Au, 1,4 ppm s.d. 9,4 ppm Ag dan 2 ppm s.d. 4 ppm Mo. Cebakan emas epitermal high sulphidation mempunyai kadar 189 ppb s.d. 1.843 ppb $\mathrm{Au}, 1 \mathrm{ppm}$ s.d. 21,4 ppm Ag dan 24 ppm s.d. 123 ppm As. Pulau Merah sesuai dengan Undang-undang Nomor 1 tahun 2014 Tentang Pengelolaan Wilayah Pesisir dan Pulau-pulau Kecil, termasuk ke dalam kriteria Pulau Kecil, oleh karena itu tidak dapat dimanfaatkan untuk kegiatan tambang. Obyek langka Pulau Merah berupa cebakan tembaga dan cebakan emas yang mudah dijangkau dan merupakan bagian dari tujuan wisata maka layak untuk dapat dijadikan cagar alam geologi.

Kata kunci: Pulau Merah, deposit tembaga, deposit emas, alterasi, mineralisasi

\section{ABSTRACT}

Red Island is located in Sumberagung Village, Pesanggaran District, Banyuwangi Regency, at a distance of about 200 meters from Sumberagung Village's coastline, has indication of metallic mineralization. The aim of the research in Red Island, obtain type of mineralization and alteration, and ore body distribution. Research methodology used is consist of observing lithology, alteration, mineralization, and rock sampling for analysis of mineral and chemical contents. Morphology of the Red Island is small hill. The eastern cliffs facing the shallow sea can be crossed at low tide, found extensive outcrops of altered and mineralized rocks. In the southeastern to the central part is encounterd a porphyry copper deposit outcrop, in the northern part encounterd a high sulphidation epitermal gold outcrop. The porphyry copper deposit consists of $0.32 \%$ to $2.14 \% \mathrm{Cu}, 285 \mathrm{ppb}$ to 1,502 ppb Au, $1.4 \mathrm{ppm}$ to $9.4 \mathrm{ppm} \mathrm{Ag}, 2$ ppm to 4 ppm Mo. The high sulphidation epithermal gold deposits consists 189 ppb to 1,843 ppb Au, 1 ppm to 21.4 ppm Ag, 24 ppm to 123 ppm As. The Red Island in accordance with the Law no. 1 of 2014 on Management of Coastal Areas and Small Islands, is included in the criteria of Small Island, therefore it prohibited for mining activities. The Red Island phenomena 
are copper deposits and gold deposits, easily accessible, and a part of a tourist destination, feasible of being a geoheritage.

Keywords: Red Island, copper deposit, gold deposit, alteration, mineralization

\section{PENDAHULUAN}

\section{Latar Belakang}

Pulau Merah terletak di Desa Sumberagung, Kecamatan Pesanggaran, Banyuwangi pada kordinat 8०36'18" LS dan $114^{\circ} 1^{\prime} 34^{\prime \prime}$ BT. Daerah ini merupakan bagian dari obyek wisata pantai Desa Pesanggaran yang berjarak sekitar 200 meter dari garis pantai dan dapat dijangkau dengan berjalan kaki pada saat laut surut. Nama Pulau Merah menjadi ikon dari obyek wisata tersebut dengan nama Obyek Wisata Pulau Merah (Gambar 1).

Di sekitar Pulau Merah dijumpai bongkahbongkah silikaan dengan tekstur vuggy, sebagai indikasi alterasi tipe high sulphidation dan bongkah-bongkah batuan mengandung stockwork urat kuarsa yang mengindikasikan mineralisasi dan alterasi tipe porfiri. Keterdapatan bongkahbongkah tersebut menjadi alasan dilakukan penelitian ini mengidentifikasi alterasi dan mineralisasi di Pulau Merah.

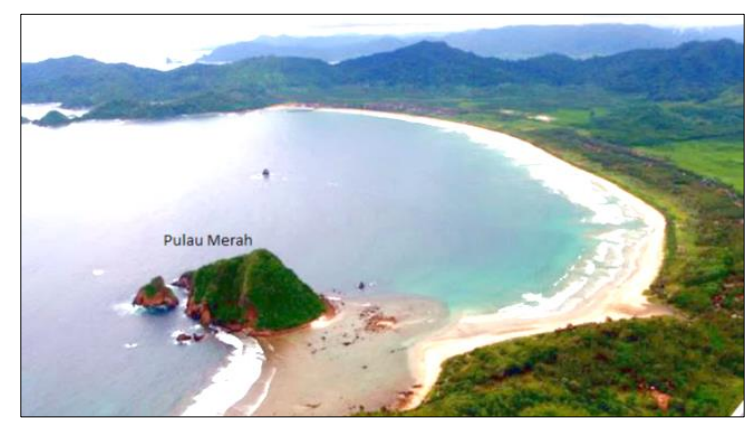

Gambar 1. Pulau Merah difoto dari arah tenggara (Sopian 2017)

Cebakan tembaga porfiri di dunia umumnya menempati jalur Asia-Pasifik (Sinclair 2004). Indonesia yang terletak di jalur vulkanik Circum Pacific, mempunyai jalur vulkanik terpanjang di dunia yaitu $15.000 \mathrm{~km}$, sepanjang $7.000 \mathrm{~km}$ telah terbukti sebagai daerah penghasil emas dan tembaga (Carlile dan Mitchell 1994) dan (Hammarstrom dkk. 2013).
Di Indonesia cebakan tembaga tipe porfiri dijumpai di beberapa lokasi di Pulau Sumatera, Jawa, Kalimantan, Sulawesi, Lombok, Sumbawa, Maluku Utara, dan Papua (Suprapto 2008). Cebakan tersebut terdapat pada daerah terpencil dengan morfologi pegunungan, sehingga sulit dijangkau,. Demikian juga keterdapatan cebakan emas tipe high sulphidation.

Penelitian di Pulau Merah dimaksudkan untuk mendapatkan data tentang sebaran mineral ekonomi dan mineral ubahan dengan melakukan pemetaan, pengambilan conto dan analisis laboratorium. Tujuan dari penelitian ini untuk mendapatkan data sebaran tipe mineralisasi dan alterasi di Pulau Merah serta sebaran tubuh bijih yang dapat digunakan sebagai acuan bagi pelaksanaan praktek eksplorasi di lapangan dan wisata pendidikan.

\section{Genesa}

Pembahasan genesa diperlukan untuk menjadi panduan dalam penelitian dan dasar analisis data hasil penelitian. Genesa mineral menyangkut aspek keterdapatan, proses pembentukan, komposisi, model, kedudukan, dan faktor-faktor pengendali terbentuknya mineral. Pembahasan tentang genesa dibatasi meliputi dua tipe mineralisasi yaitu: pembentukan cebakan tembaga tipe porfiri dan pembentukan cebakan emas epitermal tipe high sulphidation (Gambar 2).

Genesa alterasi dan mineralisasi cebakan tembaga dan emas berkaitan dengan aktivitas magma (Sillitoe 2000). Magma bergerak naik dari kedalaman menyebabkan tekanan dan temperatur turun, bahan volatil terpisah serta bermigrasi naik ke arah puncak dapur magma. Proses pemisahan tersebut menyebabkan perubahan seperti $\mathrm{pH}$ (keasaman), Eh (oksidasi), dan viskositas. Turunnya tekanan dan mendinginnya 
magma, disertai dengan kristalisasi, menyebabkan dapur magma memiliki empat fasa, terdiri dari gas, sisa magma yang masih cair, larutan air, dan padatan (kristal). Beberapa jenis logam masingmasing terpisah ke dalam fasa yang berbeda, sebagai contoh $\mathrm{Cr}$ terbentuk paling awal. $\mathrm{Cu}$ terpisah menyatu dengan larutan garam (brine), sedangkan $\mathrm{Au}$ cenderung menyatu dengan gas dan larutan air.

Cebakan tembaga porfiri terbentuk pada dapur magma dari aktivitas gunungapi. Dapur magma mendingin dari arah luar menuju ke dalam, terjadi kristalisasi mineral-mineral seperti feldspar dan kuarsa, menyebabkan magma cair yang masih tersisa menjadi kaya kandungan logam dan volatil. Unsur volatil bergerak/bermigrasi ke arah puncak dapur magma.

Bahan-bahan volatil magmatik $\left(\mathrm{H}_{2} \mathrm{O}, \mathrm{H}_{2} \mathrm{~S}\right.$, $\mathrm{SO}_{2}, \mathrm{CO}_{2}, \mathrm{HF}$ dan $\mathrm{HCl}$ ) bermigrasi dengan membawa unsur-unsur logam. Logamlogam (tembaga, molibdenum, perak, emas) tertranspot di dalam volatil, berupa komplek klorin - $\mathrm{CuCl}$. Uap panas dengan temperatur $600^{\circ} \mathrm{C}$ secara bertahap mengalami kondensasi menjadi air garam (brine) kaya kandungan logam, bermigrasi ke arah atas dan ke arah luar (lateral). Pada kondisi fluida dan volatil menjadi lebih dingin $\left(350^{\circ} \mathrm{C}\right.$ s.d. $\left.250^{\circ} \mathrm{C}\right)$ maka logamlogam mengendap yang diawali oleh Mo dan $\mathrm{Cu}$, diikuti $\mathrm{Zn}$ dan Pb (Jackson 2015).

Fluida high sulphidation berasal langsung dari unsur-unsur volatil pada magma yang terdorong naik mencapai lingkungan epitermal. Selama bergerak naik meskipun ada percampuran dengan air tanah ataupun percampuran dengan kandungan dari batuan samping yang terlewati akan tetapi dalam jumlah yang sangat terbatas. Bersamaan dengan naiknya fluida tersebut maka terjadi penurunan tekanan, komponen volatil magmatik bereaksi dengan air tanah dan air magmatik serta oksigen yang menghasilkan peningkatan $\mathrm{H}_{2} \mathrm{SO}_{4}$, pada kondisi suhu lebih rendah $\left(<300^{\circ} \mathrm{C}\right)$, (Corbett 2002).

Selanjutnya fluida asam, panas, sebagian berupa uap, bergerak naik dari magma sebagai sumbernya yang bermigrasi menuju ke permukaan dan bereaksi dengan batuan yang terlewati. Sebagai akibatnya batuan teralterasi akan mengalami leaching, feldspar terubah menjadi lempung dan sebagian lempung tersebut terbawa fluida yang meninggalkan bekas berupa lobang-lobang vuggy dan menyisakan silika. Hal ini terjadi karena silika tahan terhadap $\mathrm{HCl}$ dan $\mathrm{H}_{2} \mathrm{~S}$. Silika yang tersisa memiliki tekstur yang disebut vuggy silica atau muggy silica (Jackson 2015).

Mekanisme alterasi dan mineralisasi pada pembentukan cebakan emas high sulphidation dikontrol oleh penurunan suhu dan perubahan $\mathrm{pH}$ (keasaman) akibat interaksi dengan batuan samping dan air tanah pada lingkungan epitermal. Akibat interaksi fluida high sulphidation tersebut menyebabkan pengendapan $\mathrm{Au}-\mathrm{Ag}-\mathrm{Cu}$ dan sulfida (Corbett 2002). 


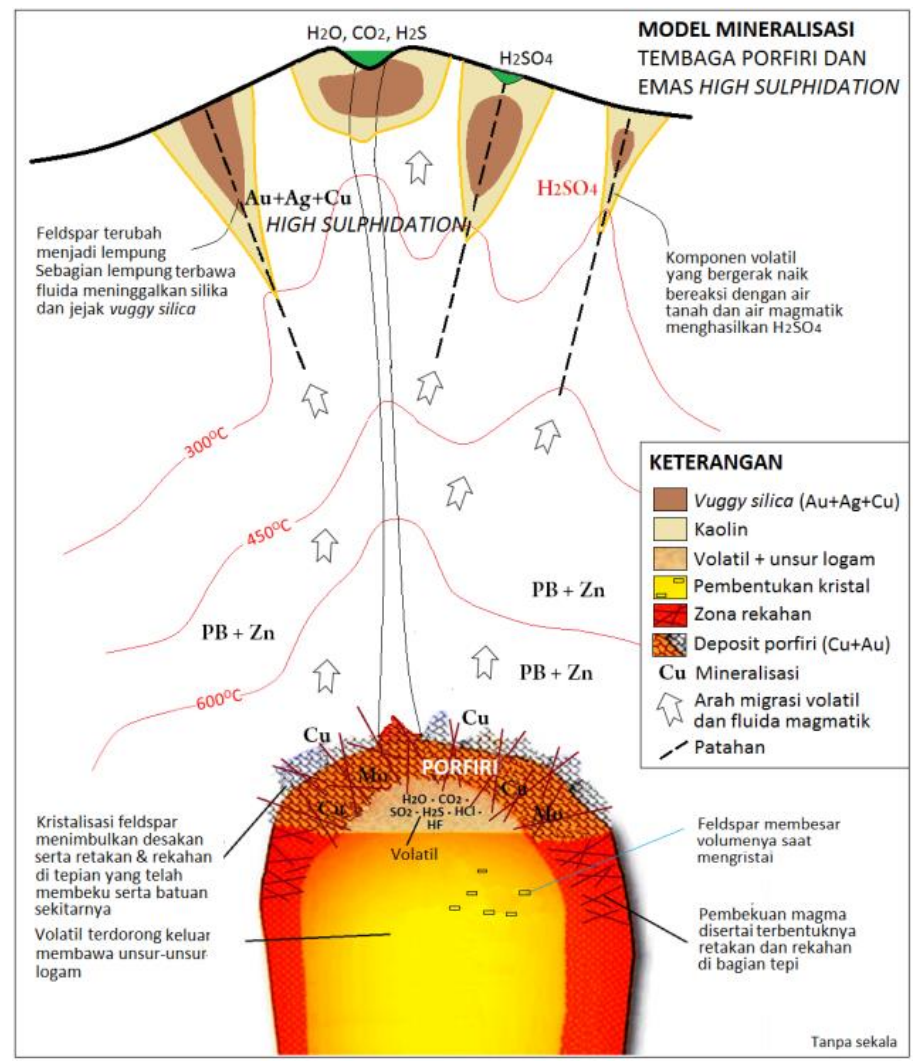

Gambar 2. Model mineralisasi tembaga porfiri dan emas epitermal high sulphidation (Sinclair 2004) dan (Jackson 2015)

\section{METODOLOGI}

Penelitian dibagi dalam dua tahapan, yaitu pengumpulan data sekunder dan pengumpulan data primer. Pengumpulan data sekunder berkaitan dengan hasil penelitian yang telah dilakukan di Pulau Merah dan sekitarnya, serta peraturan perundang-undangan. Pengumpulan data primer dengan melakukan penelitian litologi, alterasi, dan mineralisasi serta pengambilan conto batuan untuk analisis fisika dan kimia mineral.

Pengambilan conto untuk analisis kandungan unsur logam dilakukan dengan metode chip sampling, sedangkan untuk analisis alterasi menggunakan metode grab sampling. Analisis kimia mineral untuk mengetahui kandungan unsur $\mathrm{Cu}, \mathrm{Au}, \mathrm{Ag}$ menggunakan metode Atomic Absorption Spectrophotometry (AAS) dan untuk analisis unsur Mo dan As menggunakan metode kolorimetri Sedangkan analisis fisika mineral untuk alterasi dan mineralisasi menggunakan mikroskop serta analisis mineral lempung menggunakan Portable Infrared Mineral Analyzer (PIMA).

Kegiatan penelitian di lapangan dilaksanakan pada tanggal 5 dan 6 Juli 2017. Penentuan waktu kegiatan lapangan mempertimbangkan periode pasang-surut laut. Hal ini agar dapat menyeberang ke Pulau Merah dengan berjalan kaki, serta dengan surutnya air laut didapatkan singkapan batuan lebih luas. Pada saat pelaksanaan penelitian, lama waktu surut laut pada siang hari sekitar tiga jam.

Mengingat keterbatasan waktu di lapangan, maka target penelitian hanya pada singkapan di sepanjang pantai Pulau Merah dan pulau-pulau kecil di seberangnya serta dataran di seberang timur yang dapat dijangkau dengan berjalan kaki saat laut surut. Untuk menafsirkan alterasi dan mineralisasi pada bagian arah zona puncak Pulau Merah berdasarkan pada bongkah yang dijumpai di sepanjang pantai dan kaki tebing. 


\section{HASIL DAN PEMBAHASAN}

Hasil dari penelitian meliputi data hasil penelitian terdahulu dan data primer hasil pengamatan di lapangan dan di laboratorium. Secara garis besar terdiri dari geologi, alterasi, mineralisasi, dan overprint.

\section{Geologi}

Morfologi Pulau Merah berupa bukit kecil berbentuk kerucut dengan lereng pada bagian selatan dan barat umumnya terjal dan sebagian berupa tebing tegak. Sedangkan pada lereng bagian utara dan timur relatif lebih landai dengan puncak tertinggi 45 meter di atas permukaan laut. Bentuk pelamparan Pulau Merah mendekati lonjong memanjang timurlaut baratdaya dengan garis diameter terpanjang 300 meter dan lebar 150 meter. Berdasarkan Undang-Undang nomor 1 tahun 2014 Tentang Pengelolaan Wilayah Pesisir dan Pulau-pulau Kecil, Pulau Merah termasuk ke dalam kriteria pulau kecil. Jarak terdekat dari garis pantai daratan utama Pulau Jawa sekitar 200 meter yang dapat diseberangi dari arah timur saat laut surut. Bahkan pada bagian selatan dari jalur penyeberangan saat surut tidak terendam air laut sama sekali. Bagian selatan, utara, dan barat Pulau Merah berlereng sangat terjal, menghadap ke arah laut dalam (Gambar 1 dan 11).

Pulau Merah berada pada tepi tenggara dari zona sisa-sisa endapan gunung api tipe strato berumur Miosen yang mempunyai lebar sebaran mencapai $50 \mathrm{~km}$ dengan bagian tengah berupa Kubah Meru Betiri. Topografi daerah ini telah mengalami erosi kuat (Gambar 3), dan telah ditemukan beberapa daerah prospek mineralisasi tembaga dan emas (Hellman 2011).

Di sekitar Pulau Merah didominasi batuan vulkanik berupa breksi vulkanik, tuf, batupasir, dan lava andesit, serta terdapat sisipan batugamping. Batuan tersebut termasuk dalam Formasi Batuampar, diterobos oleh pluton dan retas-retas magma kalk-alkali tipe-I. Batuan terobosan terdiri dari diorit mikro, diorit, diorit hornblende, diorit kuarsa-hornblende, andesit hornblende porfiri, dan tonalit.

Alterasi di sekitar Pulau Merah sangat luas dan intensif. Penelitian di sekitar Tumpang Pitu menemukan sebaran alterasi silika, argilik, dan advanced argilic (Hellman 2011) dan (Maryono, dkk., 2016) Dari pola sebaran alterasi di daratan utama tersebut, diperkirakan sebaran alterasi yang sama menerus ke arah barat sampai di Pulau Merah (Gambar 4).

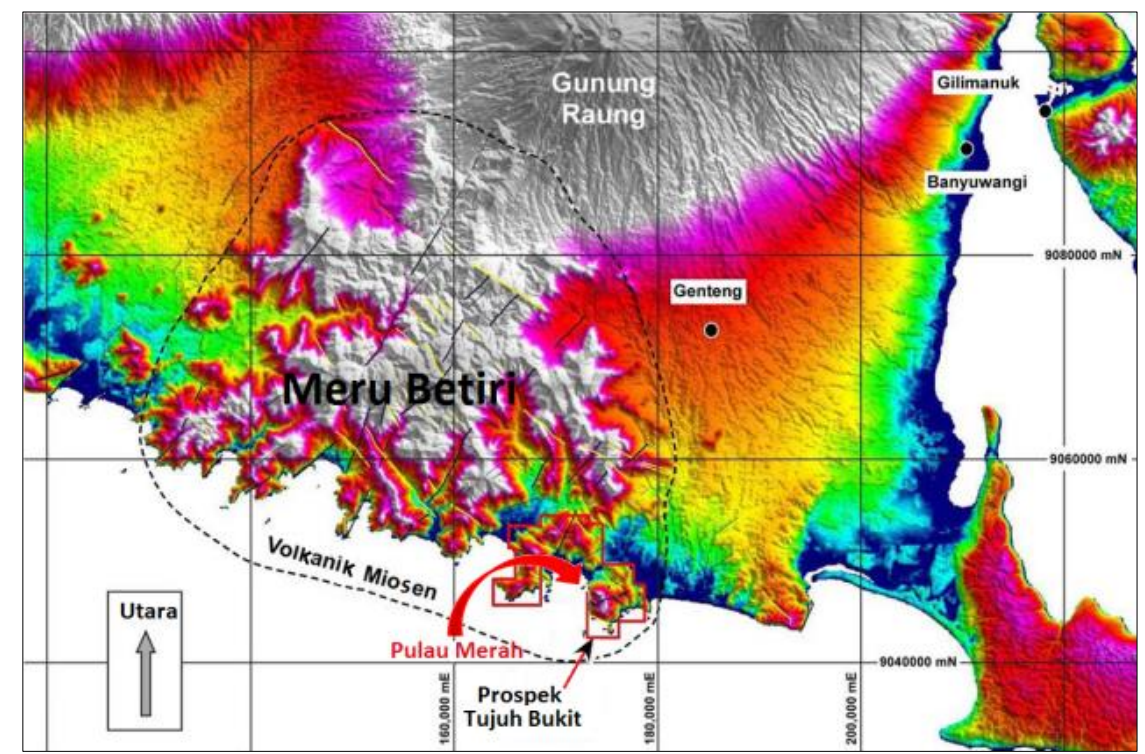

Gambar 3. Peta sebaran batuan Vulkanik Miosen dan Kuarter di Daerah Meru Betiri dan sekitarnya (modifikasi dari Hellman, 2011) 


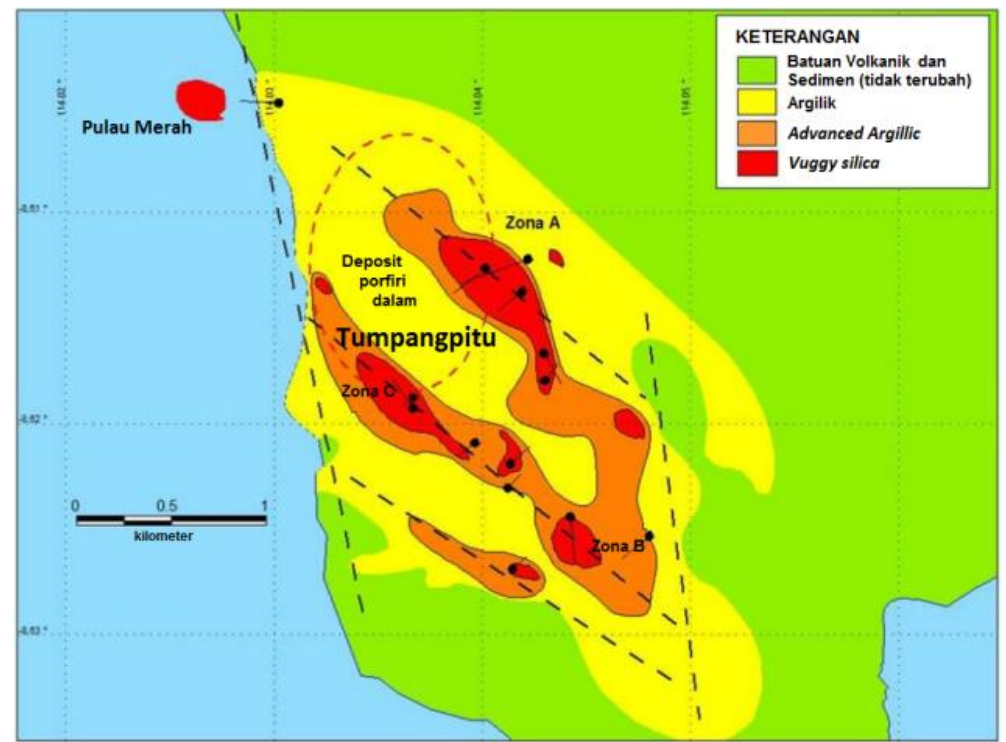

Gambar 4. Sebaran alterasi di Pulau Merah dan sekitarnya (modifikasi dari Hellman, 2011)

\section{Alterasi}

Pulau Merah tersusun atas batuan vulkanik berumur Miosen (Gambar 3), berada di bagian barat kompleks Tumpang Pitu, dibatasi oleh patahan yang membentuk kelurusan garis pantai dengan arah baratlaut-tenggara (Gambar 4).

Berdasarkan peta sebaran alterasi (Hellman 2011), seluruh Pulau Merah digambarkan sebagai zona vuggy silica.

Zona argilik mempunyai penyebaran luas di Daerah Tumpang Pitu dan sekitarnya. Hasil analisis conto yang diambil di sebelah timur Pulau Merah, mengindikasikan bahwa sebaran alterasi argilik menerus ke arah Pulau Merah, pada sebelah barat jalur patahan menempati zona yang apabila saat pasang terendam air laut.

Alterasi di Pulau Merah dapat dikelompokkan ke dalam empat zona yakni; zona bagian selatan pulau, zona bagian utara pulau, zona di seberang timurlaut pulau dan zona seberang timur pulau (Gambar 5). Singkapan zona bagian selatan dapat dijumpai pada tebing sepanjang pantai dari bagian tenggara ke arah utara sampai bagian tengah, zona utara tersingkap di sepanjang tebing bagian utara pulau, sedangkan zona seberang timurlaut berada di pulau-pulau kecil di seberang timurlaut Pulau Merah, dan zona seberang timur berada di lepas pantai timur Pulau Merah.

Pada zona bagian selatan mineral ubahan berupa silika tersebar maupun mengisi rekahan (fracture filling) serta sebagai replacement, menggantikan mineral dari batuan induk. Umumnya silika mengisi rekahan membentuk stockwork pada batuan dengan tekstur porfiritik yang mengandung sulfida tembaga tersebar serta mengisi rekahan (Gambar 6). Hasil analisis PIMA conto dari lokasi PM.02 mengandung dickite + kaolinite + jarosite conto PM.03 mengandung dickite + halloysite + kaolinite.

Pada zona bagian utara komposisi mineral ubahan dominan silika, teralterasi sangat kuat, sehingga sulit diidentifikasi batuan asalnya. Umumnya terdapat tekstur vuggy silika (Gambar 7). Batuan sangat keras, membentuk permukaan tebing dengan tonjolan runcing dan tajam. Sebaran alterasi ini terdapat di lokasi PM.07 sampai di sekitar lokasi PM.09. Hasil analisis PIMA dari conto mengandung lempung, nomor lokasi PM.09 didapat kandungan dickite + pyrophyllite + nacrite, merupakan zona alterasi tipe advanced argilic. Bongkahbongkah di sepanjang kaki tebing pada zona ini terdiri dari batuan alterasi silika, dengan tekstur vuggy silica. 


\section{MAKALAH ILMIAH}

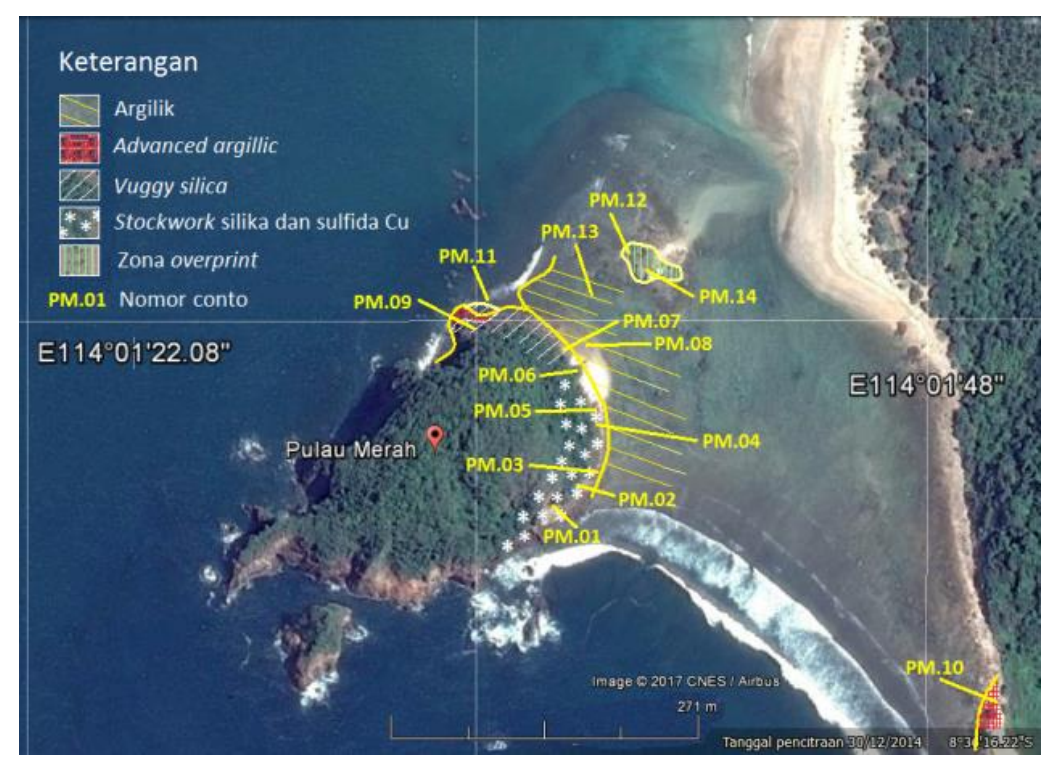

Gambar 5. Peta lokasi conto dan alterasi Pulau Merah

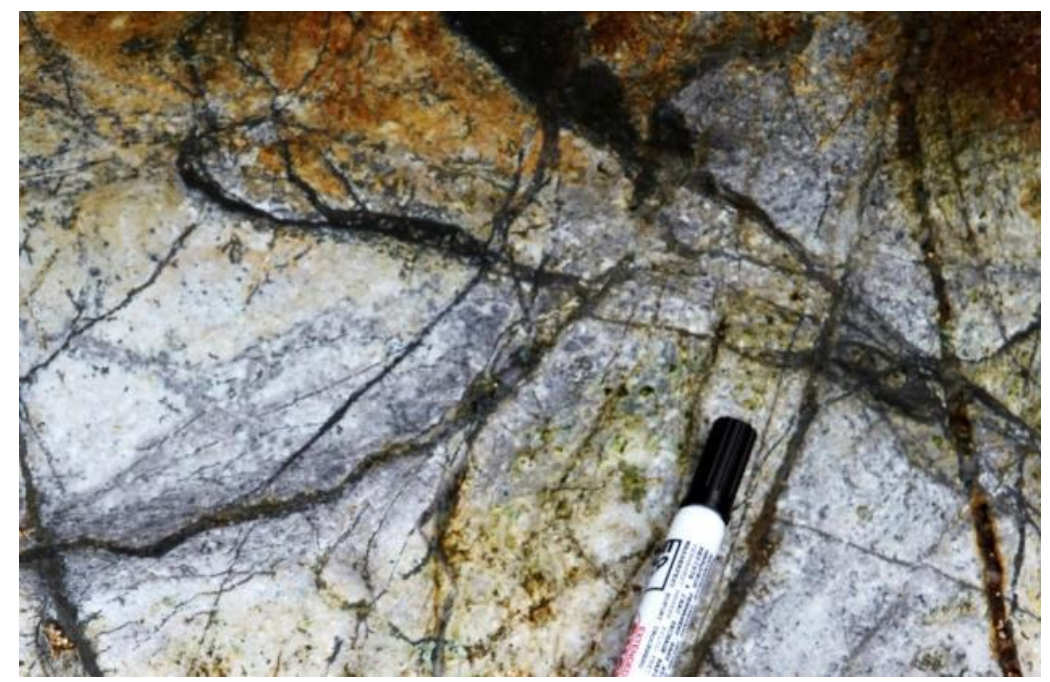

Gambar 6. Batuan porfiri terpotong urat-urat silika dan sulfida tembaga, mineral alterasi lempung berupa dickite, kaolinite, jarosite, lokasi PM.02

Zona di seberang timur pantai Pulau Merah terdapat dataran dengan batuan penyusun berupa batuan porfiritik, berwarna putih sampai dengan abu cerah, pada saat laut pasang, terendam air. Hasil analisis PIMA conto PM.08 dan PM.13 mengandung dickite + halloysite merupakan zona argilik.

Ubahan silika masif tidak hanya dijumpai di Pulau Merah akan tetapi terdapat juga di lepas pantai seberang timurlaut (Gambar 12). Zona silikaan ini membentuk tonjolantonjolan runcing, membentuk pulau-pulau kecil dengan diameter beberapa meter. Sebaran silika masif, tekstur vuggy silica, terdapat urat-urat silika struktur menjaring.
Bongkah-bongkah batuan berupa material runtuhan dari tebing, tersebar melimpah di sepanjang pantai timur sampai di bagian utara Pulau Merah. Ukuran bongkah beberapa sentimeter sampai dengan lebih dari satu meter. Seluruh bongkah merupakan batuan teralterasi. Komposisi bongkah terdiri dari dua kelompok utama. Kelompok pertama berupa bongkah batuan porfiritik, terpotong stockwork silika (porphyry style) dan stockwork mengandung sulfida tembaga dijumpai di pantai timur bagian selatan (Gambar 8).

Kelompok kedua berupa bongkah batuan tersilikakan kuat dan masif, terdapat tekstur 
vuggy silica. Sebaran kelompok kedua ini dapat dijumpai di sepanjang pantai Pulau Merah mulai dari bagian tenggara dan cenderung lebih melimpah di bagian utara. Hal ini mengindikasikan bahwa terdapat zona vuggy silica di bagian puncak, asal dari bongkah runtuhan tersebut.

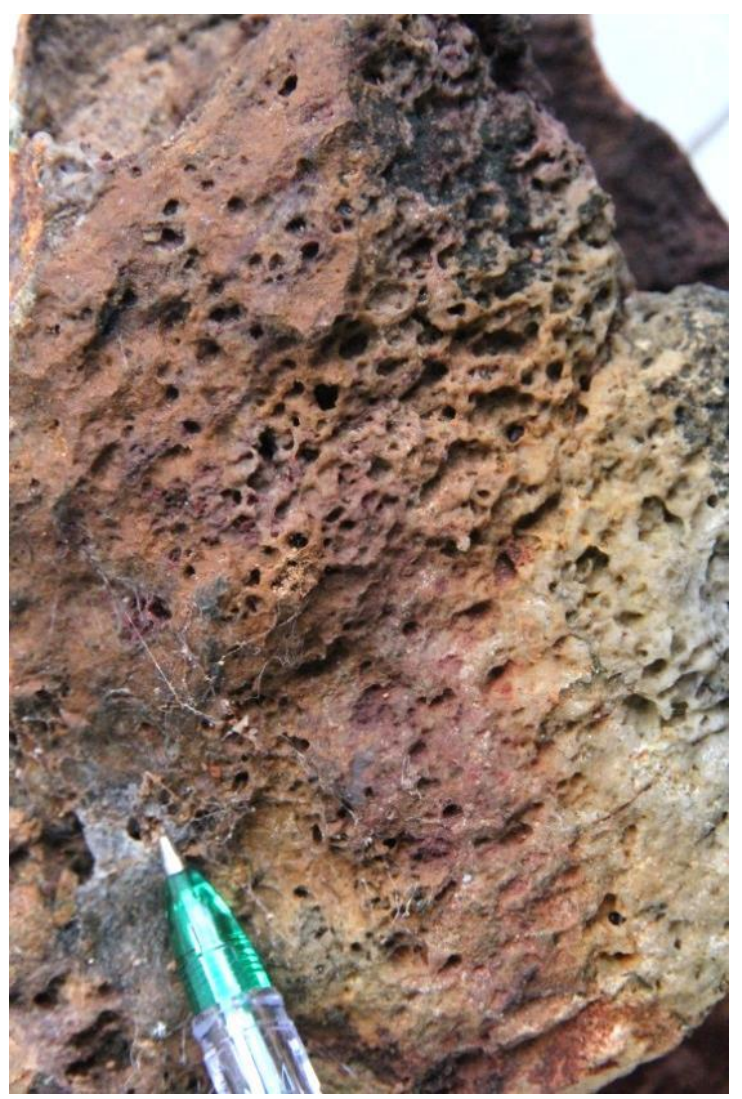

Gambar 7. Tekstur vuggy silica di lokasi PM.09

Singkapan batuan porfiritik terpotong uraturat silika dan sulfida tembaga, terdapat melimpah di tebing timur bagian selatan
Pulau Merah. Bagian bawah singkapan batuan apabila saat laut pasang berada di bawah permukaan air laut, mempunyai warna abu-abu cerah. Sedangkan singkapan batuan yang berada di atas permukaan air laut berwarna coklat, merah hati, dan hijau (Gambar 9).

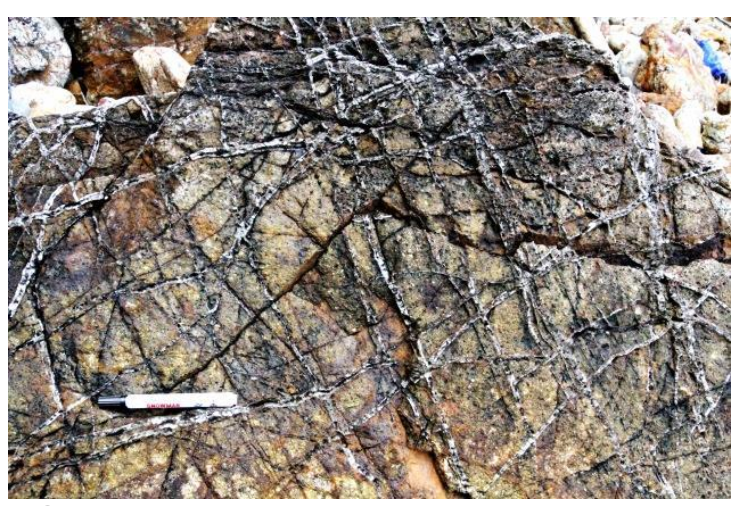

Gambar 8. Bongkah terpotong urat-urat silika dengan pola menjaring (stockwork)

Indikasi mineralisasi tembaga dapat diamati di lapangan dengan dijumpainya mineral malakit melapisi permukaan lereng tebing timur bagian selatan, sehingga memberikan warna hijau pada permukaan tebing, serta terdapat stockwork mengandung malakit, kalkosit, kalkopirit, bornit, dan azurit. Sebaran malakit dijumpai lebih menonjol dibandingkan mineral tembaga jenis yang lain, selain menutup permukaan singkapan di tebing timur bagian selatan Pulau Merah, malakit dijumpai juga mengisi rekahan, membentuk pola struktur menjaring (stockwork) (Gambar 10).

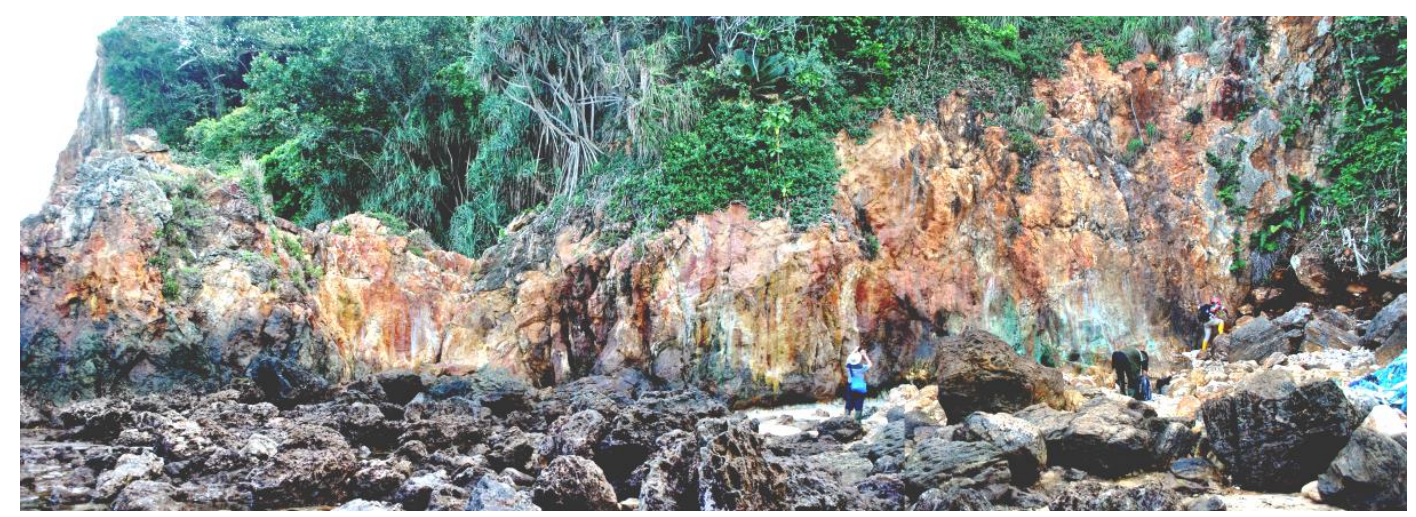

Gambar 9. Singkapan batuan mengandung silika, malakit, kalkosit, dan kalkopirit, serta pirit, lokasi PM.01 


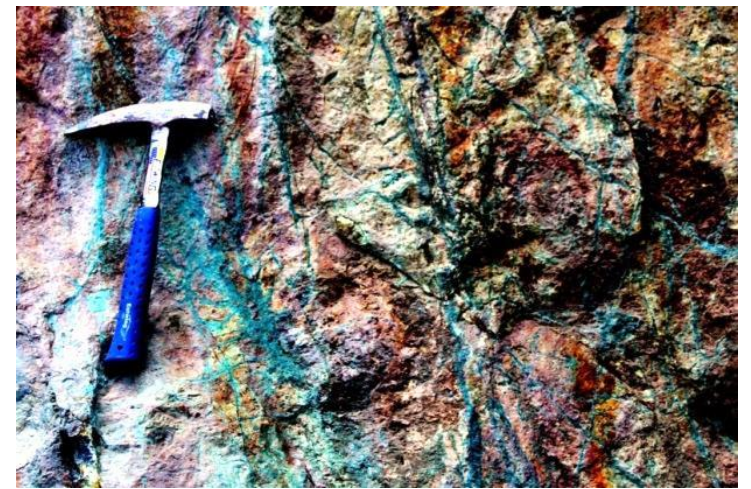

Gambar 10. Batuan porfiritik mengandung malakit tersebar dan mengisi rekahan, lokasi PM.01.

Mineral-mineral tembaga jenis yang lain dapat teramati dengan jelas menggunakan lensa pembesar atau menggunakan mikroskop binokuler. Pengamatan menggunakan mikroskop binokuler dengan perbesaran 5 kali sampai dengan 104 kali, didapatkan kenampakan sebaran mineralmineral tembaga lebih jelas dan lengkap. Kandungan kalkopirit, kalkosit, bornit dijumpai tersebar maupun mengisi rekahan. Sebagian kalkopirit membentuk pola kelurusan dan stockwork seperti pada Gambar 15.B. Malakit umumnya tersebar di sekitar sulfida tembaga yang lain (Gambar 15. A, D, \& F). Mineral azurit membentuk selaput tipis menutup permukaan rongga (Gambar 15.H). Mineral bornit tersebar maupun mengisi rongga membentuk urat halus. Demikian juga mineral kalkosit tersebar dan mengisi rongga membentuk urat-urat halus (Gambar 15.G).

Hasil analisis kimia, semua conto dari zona mineralisasi, mengandung $\mathrm{Cu}, \mathrm{Au}$, dan Ag tinggi, sebagaimana umumnya kadar pada cebakan tembaga dan emas yang dapat diusahakan secara ekonomis. Jumlah conto yang dianalisis kandungan logamnya sebanyak 14, terdiri dari 11 conto dari hasil identifikasi di lapangan terdapat indikasi mineralisasi, sedangkan tiga conto dari zona alterasi argilik dan advanced argillic. Kandungan tembaga tinggi terdapat pada lokasi PM.01 sampai PM.06, menempati bagian selatan dari tebing timur Pulau Merah. Hasil analisis kimia conto bijih tembaga diperoleh kadar $0,32 \%$ s.d. $2,14 \%$ Cu, 285 ppb s.d. 1.502 ppb Au, 1,4 ppm s.d.
9,4 ppm Ag dan , 2 ppm s.d. 4 ppm Mo (Gambar 11). Berdasarkan indikasi lapangan berupa batuan porfiritik, terpotong stockwork mengandung silika dan sulfida tembaga, serta indikasi alterasi lempung berupa mineral dikit, halosit, dan kaolin, kandungan tinggi tembaga, emas dan perak maka zona mulai dari lokasi PM.01 sampai PM.06 merupakan cebakan bijih tembaga-emas tipe porfiri.

Zona mineralisasi di bagian utara Pulau Merah, mulai dari sekitar lokasi PM.07 sampai PM.13, merupakan deposit epitermal. Hasil analisis kimia bijih emas mempunyai kadar 189 ppb s.d. 1.843 ppb Au, 1 ppm s.d. 21,4 ppm Ag dan 24 ppm s.d. 123 ppm As. Kandungan emas tinggi di lokasi PM.11 yaitu 1.843 ppb Au dan lokasi PM.12 yaitu 1.037 ppb Au. Lokasi PM.11 berada sekitar 50 meter di utara lepas pantai Pulau Merah dan PM.12 di sekitar 100 meter di timurlaut lepas pantai Pulau Merah (Gambar 11). Zona mineralisasi di bagian utara dicirikan oleh adanya alterasi silika masif, tekstur vuggy silica, dengan kandungan lempung pada tubuh bijih di lokasi PM.09 berupa dickite + pyrophyllite + nacrite, merupakan cebakan emas epitermal tipe "high sulphidation". Cebakan emas epitermal tipe high sulphidation, disebut juga tipe "asam sulfat" (White dan Hedenquist 1995). Kehadiran dickite + pyrophyllite + nacrite mengindikasikan lingkungan asam sampai menengah dengan suhu $200^{\circ} \mathrm{C}$ s.d. $300^{\circ} \mathrm{C}$ (Chen, Wang, dan Yang 2001).

Oksida besi berupa hematit, jarosit, dan limonit melapisi permukaan singkapan deposit bijih tembaga maupun bijih emas. Kandungan besi berupa pirit teramati pada mikrokskop binokuler (Gambar 15.B). Kehadiran oksida besi menutupi permukaan singkapan pada dinding tebing dan lereng Pulau Merah memberikan kenampakan warna coklat dan merah hati. Singkapan warna coklat dan merah hati tersebut dapat dijumpai di tebing timur bagian selatan, tebing barat, serta bagian bawah tebing sepanjang pantai Pulau Merah. Lereng timur bagian utara relatif lebih landai tertutup oleh rimbunan pohon, 
sehingga tidak memberikan kenampakan warna merah.

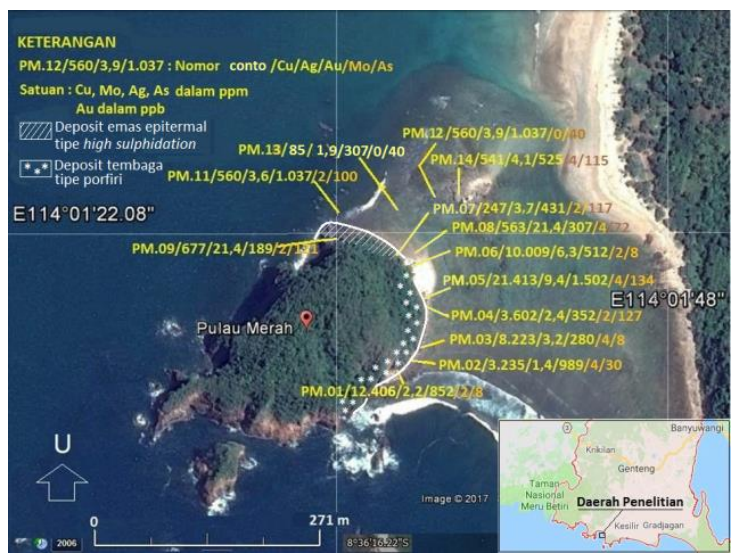

Gambar 11. Peta lokasi conto, kandungan logam, dan sebaran singkapan mineralisasi.

\section{Overprint}

Di bagian timur laut Pulau Merah terdapat indikasi adanya zona overprint. Pada zona tersebut, dijumpai ciri khas dari dua tipe mineralisasi tersebut (Gambar 13 dan 14). Terdapat jejak salah satu ciri khas mineralisasi tembaga tipe porfiri, yaitu jejak-jejak pola stockwork (Gambar 13 A) yang sebagian terisi silika, serta jejak berupa rongga-rongga kosong membentuk pola stockwork (Gambar 13 B dan C), terdapat tekstur vuggy silica, ciri khas mineralisasi emas high sulphidation (Gambar 13 A dan C).

Secara genesa zona overprint dihasilkan ketika bijih tembaga porfiri telah terbentuk, proses pendinginan magma masih berlanjut sampai mencapai suhu $<300^{\circ} \mathrm{C}$. Cebakan bijih tembaga porfiri yang telah terbentuk sebelumnya pada suhu $>600^{\circ} \mathrm{C}$ tersebut, terubah kembali oleh aktifitas hidrotermal dalam lingkungan asam sulfat, suhu $<300^{\circ} \mathrm{C}$, menghasilkan alterasi silika masif dengan tekstur vuggy silica atau terubah kembali oleh hidrotermal dari sumber magmatik yang berbeda. Hal ini mengingat di sekitar Pulau Merah terjadi beberapa kali terobosan magma (Hellman 2011) dan (Maryono, dkk., 2016), sehingga sumber hidrotermal yang mengontrol proses alterasi dan mineralisasi bisa terdiri dari lebih dari satu generasi intrusi yang berbeda.

Zona overprint dijumpai di seberang timurlaut Pulau Merah, sekitar 100 meter dari tepi pantai, membentuk morfologi berupa tonjolan-tonjolan pulau kecil dengan diameter beberapa meter. Saat laut pasang maksimum, sebagian besar berada di bawah permukaan air.

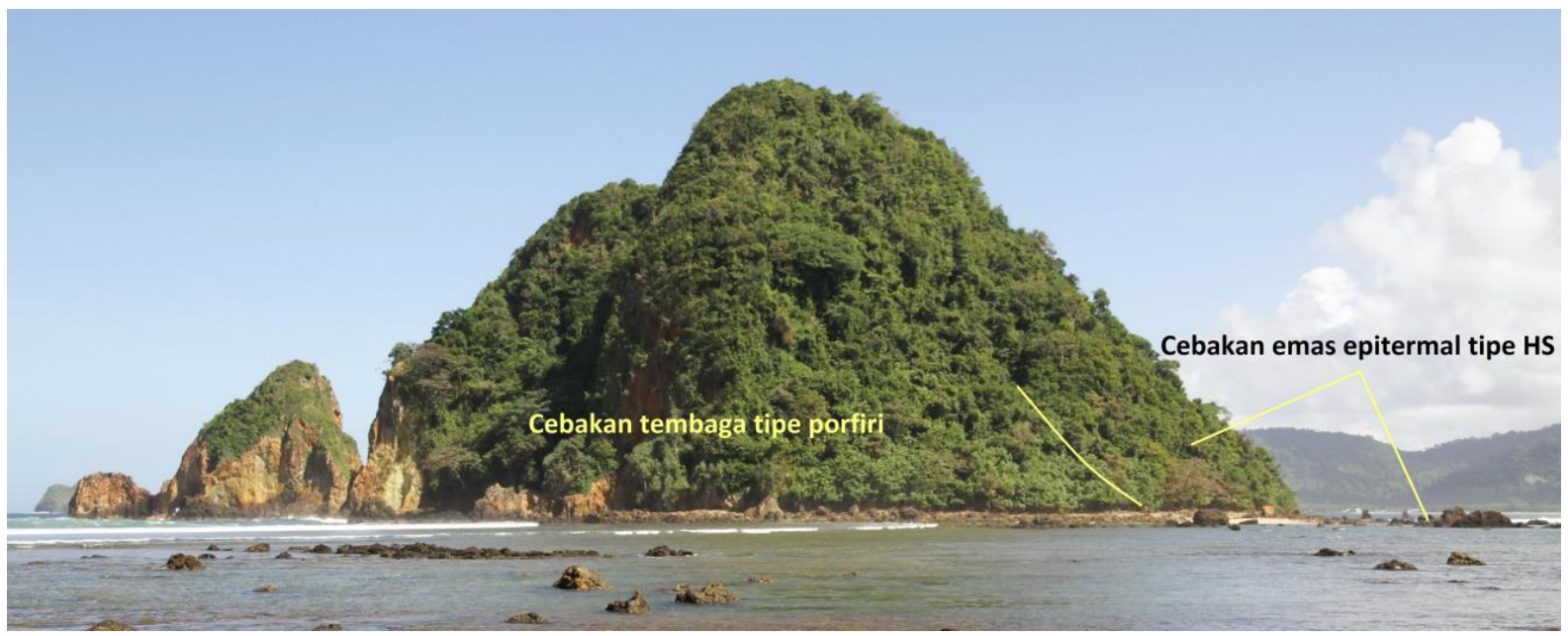

Gambar 12. Cebakan tembaga tipe porfiri dan cebakan emas epitermal tipe high sulphidation Pulau Merah, difoto dari arah tenggara 


\section{MAKALAH ILMIAH}

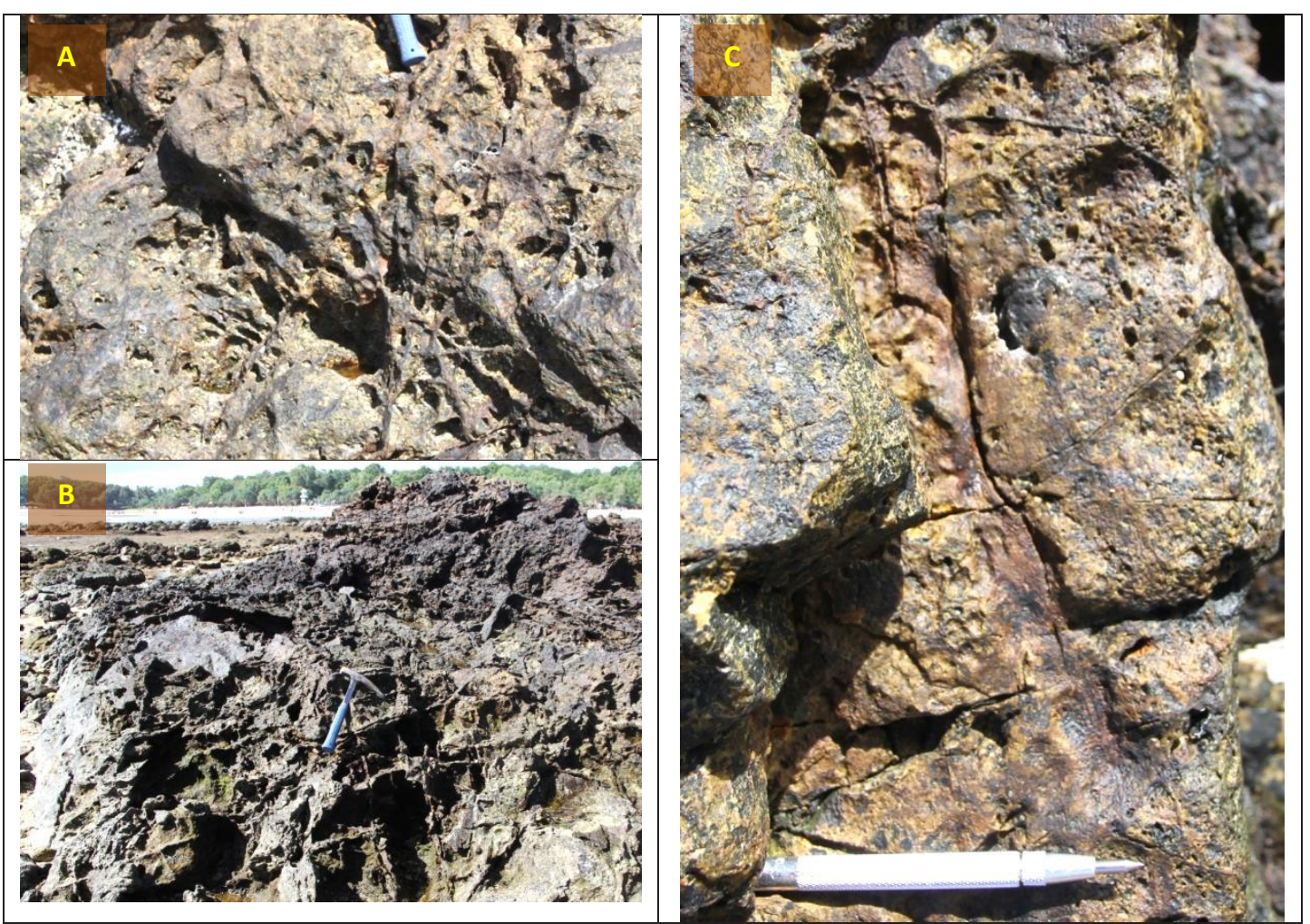

Gambar 13. Zona overprint di seberang timurlaut Pulau Merah membentuk tonjolan dan pulau-pulau kecil. A di lokasi PM.14, terdapat jejak stocwork silika. B di lokasi PM. 13 dan C lokasi PM. 14 terdapat jejak rongga-rongga membentuk pola stocwork.

Pada A dan C terdapat tekstur vuggy silica.

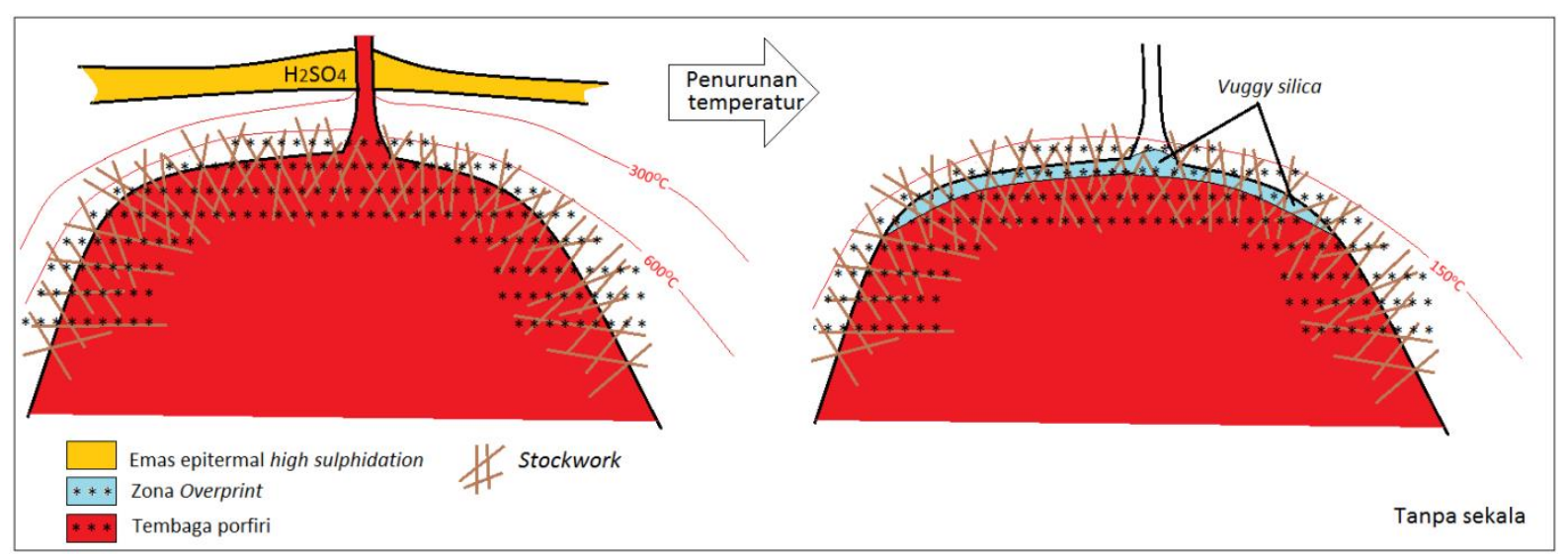

Gambar 14. Diagram overprint Pulau Merah 


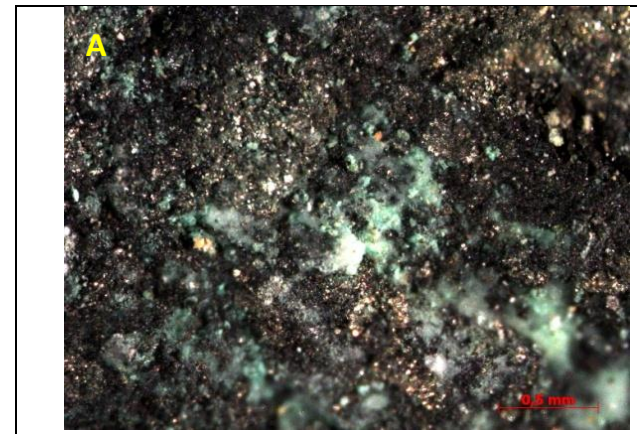

PM.01. Kandungan mineral kalkopirit (kuning), kalkosit (abu-abu gelap) dan malakit (hijau), perbesaran $58 \mathrm{x}$.

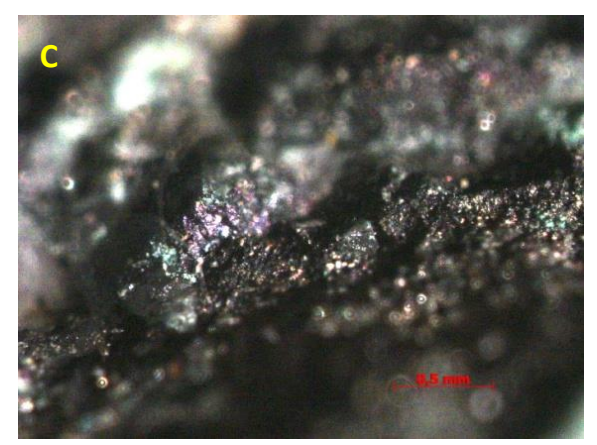

PM.01. Mineral bornit tersebar dan mengisi rekahan, perbesaran $64 \mathrm{x}$

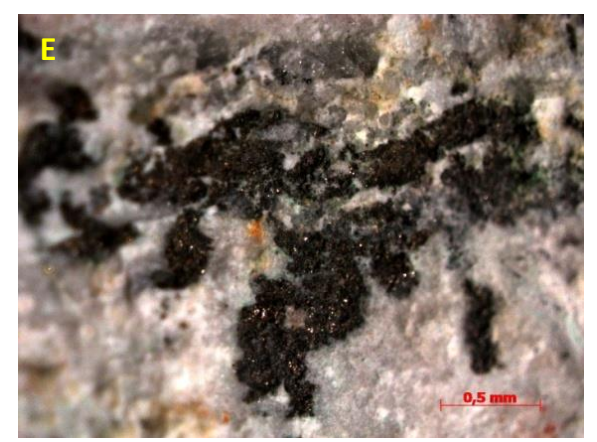

PM.03. Mineral kalkosit (abu-abu gelap) tersebar, perbesaran $30 \mathrm{x}$.

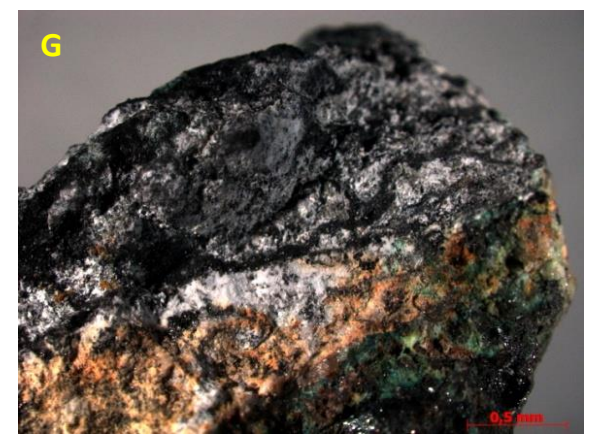

PM.05. Mineral kalkosit (abu-abu gelap) mengisi rekahan, perbesaran $5 \mathrm{x}$.

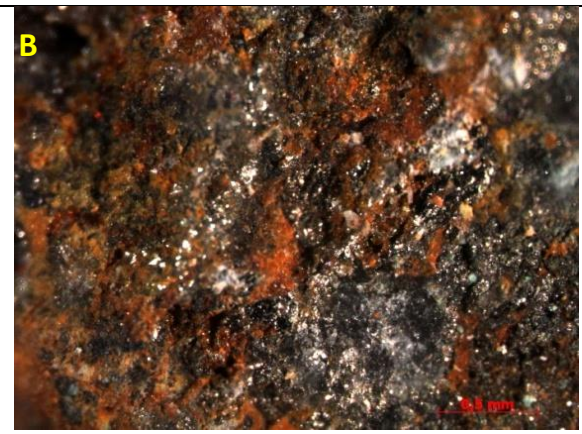

PM.01. Kelurusan-kelurusan warna kuning emas, mineral pirit dan kalkopirit mengisi rekahan, perbesaran $39 \mathrm{x}$.

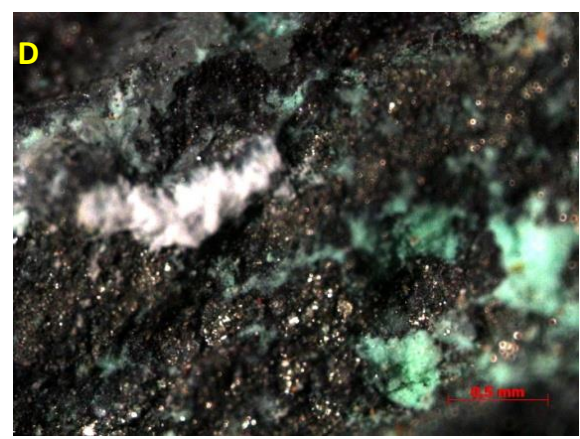

PM.01. Mineral bornit (ungu) dan malakit (hijau), perbesaran $46 \mathrm{x}$

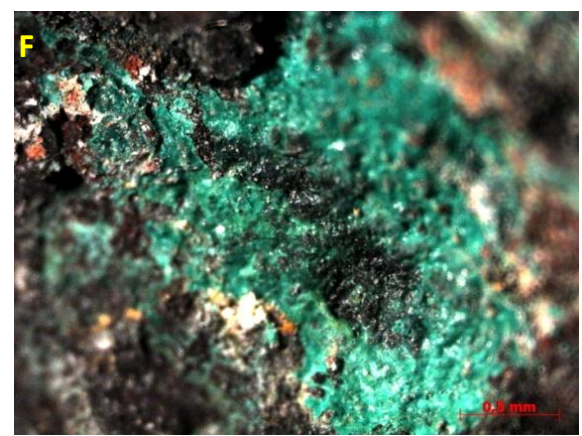

PM.05. Mineral kalkosit (abu-abu gelap) dikelilingi malakit (hijau), perbesaran $25 \mathrm{x}$

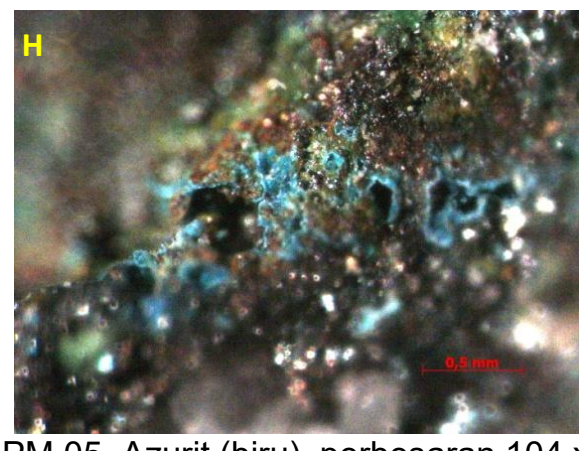

PM.05. Azurit (biru), perbesaran $104 x$

Gambar 15. Hasil perbesaran menggunakan mikroskop binokuler, conto cebakan tembaga porfiri 


\section{KESIMPULAN DAN SARAN}

Keseluruhan Pulau Merah merupakan tubuh dari cebakan bijih. Terdapat dua tipe alterasi dan mineralisasi yang terbentuk yaitu tembaga porfiri $\mathrm{Cu}-\mathrm{Au}$ dan emas epitermal tipe high sulphidation. Alterasi epitermal high sulphidation dicirikan oleh alterasi silika masif, dengan tekstur vuggy silica. Di bagian utara Pulau Merah zona vuggy silica berbatasan dengan zona advanced argillic. Sedangkan tipe porfiri dicirikan oleh stocwork silika dan stockwork sulfida tembaga, pada bagian timur Pulau Merah berbatasan dengan zona argilik.

Cebakan tembaga porfiri $\mathrm{Cu}-\mathrm{Au}$ mempunyai kadar $0,32 \%$ s.d. $2,14 \% \mathrm{Cu}$, 285 ppb s.d. 1.502 ppb Au , 1,4 ppm s.d. 9,4 ppm Ag dan 2 ppm s.d. 4 ppm Mo. Cebakan bijih emas epitermal high sulphidation mempunyai kadar 189 ppb s.d. 1.843 ppb Au, 1 ppm s.d. 21,4 ppm Ag dan 24 ppm s.d. 123 ppm As. Pada bagian arah puncak pulau diperkirakan terdapat zona vuggy silica. Di antara dua tipe mineralisasi tersebut terdapat zona overprint, yaitu cebakan tembaga porfiri yang telah terbentuk sebelumnya di-overprint epitermal high sulphidation.

Fenomena geologi Pulau Merah berupa tubuh cebakan bijih tembaga porfiri $\mathrm{Cu}-\mathrm{Au}$ dan cebakan bijih emas epitermal high sulphidation yang berada pada satu lokasi dengan singkapan lengkap dan luas, mudah dijangkau, serta berada pada lingkungan obyek wisata, maka hal tersebut merupakan fenomena geologi yang langka di Indonesia. Sehingga Pulau Merah layak untuk dijadikan cagar alam geologi agar dapat dilestarikan kondisi alaminya dan dapat dimanfaatkan sebagai obyek wisata pendidikan geologi (geowisata).

\section{DAFTAR PUSTAKA}

Carlile, J. C., dan Mitchell, A.H.G. 1994. "Magmatic Arcs and Associated Gold and Copper Mineralization in Indonesia." Journal of Geochemical Exploration 50 (1-3): 91-142. https://doi.org/10.1016/03756742(94)90022-1.

Chen, P.Y., Yuan, M.K., dan Yang, D.S. 2001. "Mineralogy of Dickite and Nacrite from Northern Taiwan." Clay Minerals 49 (6): 586-95.

Corbett, G.J. 2002. "Epithermal Gold for Explorationists." AIG Journal, Applied Geoscientific Practice and Research in Australia, no. February: 2002-01. http://www.korearth.net/down/doc/Co rbett.pdf.

Hammarstrom, J.M., Bookstrom, A.A., Dicken, C.L., Drenth, B.J., Ludington, S., Robinson, G.R., Bambang, T.S., dkk. 2013. "Porphyry Copper Assessment of Southeast Asia and Melanesia." Global Mineral Resource Assessment, no. Scientific Investigations Report 2010-5090-D: 352.

Hellman, P.L. 2011. "Tujuh Bukit Project Report on Mineral Resources, Technical Report for Interprid Mines Limited." NSW. http://member.afraccess.com/media ?id=CMN://6A437115\&filename $=200$ 90204/00924543.pdf.

Jackson, A. 2015. "Pophyry Copper Deposits."2015.

http://sprottglobal.com/naturalresource-investing/investmentuniversity/ore-deposits-101-part-3.

Maryono, A., Harrison, R., Rompo, I., Priowasono, E., Norris, M. 2016. "Succssesfull Techniques in Exploring The Lithocap Environement of The Sunda Magmatic Arc, Indonesia." In Proocedings of Unconventional Exploration Targets \& Latest Techniques and New Tools in Mineral and Coal Mgei 8 Annual Convention 2016, edited by Darlius E.Y., 7-13. Bandung: MGEI. 
Sillitoe, R.H. 2000. "Gold -Rich Porphyry Deposits: Descriptive and Generic Models and Their Role in Exploration and Discovery." SEG 13 (2000): 31545.

Sinclair, W.D. 2004. "Porphyry Deposits." Distribution 33 (2004): 1-14.

Sopian, A. 2017. "Surga Surfing Di Pantai Merah."

2017.

https://maritimenews.id/surga-

surfing-di-pantai-merah.
Suprapto, S.J. 2008. "Pertambangan Tembaga Di Indonesia." Warta Geologi, September 2008. http://www.bgl.esdm.go.id/index.php/ koleksi-warta-geologi/242-wartageologi-volume-iii-no-3.

White, N.C. dan Hedenquist, J.W. 1995. "Epithermal Gold Deposits: Styles, Characteristics and Exploration." Published in SEG Newsletter 1 (23): 9-13.

https://doi.org/10.1080/00207540410 001683261.

\begin{tabular}{|ll|}
\hline Diterima & $:$ 24 Januari 2018 \\
Direvisi & $:$ 19 Juli 2018 \\
Disetujui & $:$ 13 Agustus 2018 \\
\hline
\end{tabular}

